\title{
Cone-beam Computed Tomography Analysis of the Frontal Sinus in Forensic Investigation
}

\author{
Análisis de Tomografías Computarizadas de Haz Cónico \\ del Seno Frontal en la Investigación Forense
}

\author{
Jeidson Antonio Morais Marques*; Jamilly de Oliveira Musse*; Bruno Cabús Gois**; \\ Luis Carlos Cavalcante Galvão ${ }^{* * * *}$ \& Luiz Renato Paranhos*****
}

MARQUES, J. A. M.; MUSSE, J. O.; GOIS, B. C.; GALVÃO, L. C. C. \& PARANHOS, L. R. Cone-beam computed tomography analysis of the frontal sinus in forensic investigation. Int. J. Morphol., 32(2):660-665, 2014.

SUMMARY: The frontal sinuses can provide significant evidence for forensic identification. The peculiarity of the frontal sinus contours allows a precise and meticulous analysis, reducing the risk of errors on the part of the forensic experts. To describe the use of cone-beam computed tomography as an alternative to obtaining images of the frontal sinuses. In addition, it is proposed the adoption of some anatomic references to do the axial slicing, which should have its plan being tangent to the upper limit of the orbital cavities, as well as the sagittal slicing, which should be done under the midline, so that all sinus boundaries would be observed while error margin in obtaining comparative images would be reduced. The comparison of frontal sinus images by cone-beam computed tomography can be used as an additional method in the identification process, providing the expert with a greater reliability.

KEY WORDS: Computed tomography; Frontal sinus; Forensic medicine.

\section{INTRODUCTION}

Identity consists of a group of characters individualizing a person or something, making it to differ from others. It is a set of attributes that make someone or something equal only to self. To identify is to determine the individuality, or it is to prove by means of technical or scientific means that a person is that one and not another It is the act by which identity is established (Alves, 1965).

Human identification is not a difficult task, when it is about a live individual or a cadaver chronologically recent and intact. However, when there is not a complete skeleton, but a group of bones, a bone alone or just part of it, the identification process becomes progressively harder and sometimes impossible to be accomplished (Arbenz, 1988).

The anthropological knowledge is of great importance for the identification of human skeletons. Frequently, when a heap of bones is found, not all bones are present and many times only the cranium (Figini et al., 2003) is found, which can be the principal anatomic structure to be used to identify individuals (Silva, 1997).
Often, forensic doctors or dental surgeons are called to provide clarification to the court of justice about the origin and classification of the bone material found. In these cases, it becomes necessary to carry out a reconstructive or total identification.

An identification tool to be used when reliable means are not available is the comparison between old and recent radiographs belonging to the individual under suspicion. The radiographs of cranium, face, long bones and tooth have been the most used ones. Among them, face radiographs are better considered to forensic identification, particularly because of the presence of frontal and maxillary sinuses whose geometrical contours allow a precise superimposition into an identity (França, 2004).

Nevertheless, the radiographies used for comparison may show incompatibility due to processing or storage errors or even in the direction of the beam during exposure. These events can make the investigation process difficult, bringing up doubts regarding the identification of the missing person.

\footnotetext{
* Adjunct Professor, Forensic Dentistry, Health Department, Feira de Santana State University, Bahia, Brazil.

** Forensic Dentist.

*** Titular Professor, Forensic Dentistry, Health Department, Feira de Santana State University, Bahia, Brazil.

${ }^{* * * * *}$ Adjunct Professor, Forensic Dentistry, Department of Dentistry, Federal University of Sergipe, Sergipe, Brazil.
} 
With the advent of computed tomography - which shows higher precision to diagnose traumas of cranium - the number of image requests by professionals has increased, making possible the use of this technique to support human identification by comparing images of the frontal sinuses as well as those of other anatomical structures of the cranium. The images obtained can be filed and retrieved at an opportune moment (Silva et al., 2011). Therefore, it is necessary for the professional to request the inclusion of the frontal sinus region in the exam.

Among other indications of this supplementary exam is the need for observing the facial sinuses. Dentists have benefited from the technology applied in the researches on abnormalities affecting the TMJ, maxillary sinus and from the studies on implant placement. This has brought a huge demand from patients to perform CT scans of the face, creating an important source of data for future judicial investigations that should be considered timely. Thus, the objective of this study is to present and discuss the use of cone-beam computed tomography in forensic investigations.

\section{LITERATURE REVIEW}

Since human beings began to live in society, there has been a concern of knowing oneself, physical characteristics as well as internal and external variations. Such recognition processes have been improved and, currently, one can make an identification by not only qualitative but also quantitative methods and techniques.

The cranium can be used to identification through qualitative or quantitative methods (Jayaprakash et al., 2001) and can be analyzed directly or indirectly by means of radiographic exams. These can provide consistent data when used to human identification. Accordingly, the following aspects can be analyzed: trabeculated bone, teeth, alveolar bone, anatomic accidents, and contours of cavities and sinuses.

The frontal sinuses are located in the frontal bone, and similarly to the majority of cranial hollow cavities (sphenoidal sinus, frontal sinus, ethmoid cells and maxillary sinus) are pneumatics cavities covered by a mucous membrane with direct or indirect communication with the respiratory system (Quatrehomme et al., 1996; Aydinlioglu et al., 2003; Silva et al.).

The frontal sinuses begin developing between 2 and 3 years old. These are not detectable radiographically until the age of 4 to 6 , and then gradually become bigger and more complex. Their development is fast until puberty and normally is completed by 20 years old. There are many factors that can modify the normal morphology of the frontal sinus, for instance: athletes - the higher ventilation during the exercises favors an increase the intern pressure of cavities, leading to a hyperpneumatization in addition to pathologies, severe infections, tumors and fractures (Cameriere et al., 2005; da Silva et al., 2009; Silva et al.). Generally, the frontal sinuses are bigger in men than women and have their contours delimited according to environment influence and individual genetics (Quatrehomme et al.).

In human beings, the frontal sinus is commonly divided into two pieces (left and right) by a sinus septum (Prossinger \& Bookstein, 2003). Its development begins from the anterior upper extremity of infundibulum, and it is initially located in the medial part of the eyebrow arch. It broadens, extending upwardly and laterally between the inner and outer laminas, and may extend to the front of the orbit roof. The septum between the two frontal sinuses is also asymmetrical. The frontal sinus walls are rarely smooth, because there may be found sickle-shaped ridges, especially the upper wall (da Silva et al.; Silva et al.).

Based on linear measures, Ribeiro (2000) standardized a person identification method by comparative analysis of posterior-anterior radiographs of the frontal sinuses. Firstly, he drew a base line (a straight line that connected the upper boards of orbit cavities). Then, four perpendicular lines were drawn over that base line: two determining the maximum lateral of both walls of the frontal sinus, and the other two being perpendicular to the base line, reaching the top of the frontal sinus.

The measurement of the distance between these two lines perpendicular to the base line allowed to obtain: the maximum distance between the first and fourth line, which is related to the greatest diameter of both frontal sinuses; the distance between the second and third line, which indicates the highest points of the frontal sinuses; the distance between the first and second line, related to the lateral borders with the highest point of the right side; and, finally, the distance between the third and fourth line, related to the lateral borders with the highest point of the left side. In his study, the author concluded that it is valid to identify a person by linear metrics using ante- and post-mortem radiographs.

Quatrehomme et al. reported two cases of forensic identification by means of the frontal sinuses, achieving positive results and therefore showing a real possibility of identification by this method. Kirk et al. (2002) carried out a survey showing 39 cases of criminal investigations that occurred in Toronto (Canada) and were elucidated by the 
frontal sinuses analysis. The authors pointed out the validity and importance of this type of analysis for the forensic field.

The frontal sinuses radiographs can be considered as a complementary exam in human identification. In this respect, there are many methods that can be used which provide valid and precise data. The identification results from the morphometric comparison of the maxillary sinuses ante- and post-mortem, with regard to forms, size and contours in the images available (Quatrehomme et al.).

The advent of cone-beam computed tomography machines has been responsible for several benefits to the imaging study of the face, favoring a significant increase in the indication of patients to undergo this exam. Some authors (Araki et al., 2004; Mol et al., 2005) consider that such technique can reproduce relevant images to observe dentomaxillofacial disorders. They have used this technique to obtain measurements and angulations regarding the maxillofacial complex, as well as to observe anatomic structures and use that to assist in the preoperative planning.

Yang et al. (2004) used computed tomography to evaluate preoperative conditions in 80 patients undergoing frontal sinus surgery. For this, they undertaken measurements of areas and structures related to the frontal sinus with the aid of a software. In accordance with that, Aydinlioglu et al., opted by computed tomography to observe anatomic characteristics of the frontal sinus in 1,200 cases.

Ripiert et al. (2001), also used CT to analyze the frontal sinuses in thirty craniums, finding a large variability not only among the pieces under investigation, but also inside the same cranium at different positions. Smith et al. (2002) described a case in which an ante- and post-mortem CT scans of the cranium was used to identify a missing person. In such a case the frontal sinus was one of the structures considered in the identification process.

\section{DISCUSSION}

The identification process compares characters, looking for coincidences among past and current data. In other words, identification is a set of diversified procedures to individualize a person or object and is of great importance not only for juridical purposes, but also for the social and affective aspects involved (Vanrell, 2009).

The forensic anthropology services of Legal Medicine Institutes commonly receive human skeletons to be examined. However, these institutes sometimes receive only parts of skeletons or isolated bones, which increases the difficulty to obtain biotypological data. When there is not a complete skeleton, the identification might be impossible to be accomplished. The importance of forensic dentistry in the Legal Medicine Institutes has become evident and effective, by playing a role in the identification of unidentified bodies, identification of criminals (Silva), estimative of age, stature, race, and esthetic and functional loss.

The frontal sinus characteristics and its applicability for criminal investigations have been studied for many years, particularly in edentulous individuals (Cameriere $e t$ $a l$.). Its use in successful identifications has been widely accepted by anthropologists, radiologists, pathologists and the court of justice as judicial evidence with scientific validity (Hashimoto et al., 2003). The irregular forms of the frontal sinuses, initially observed in anterior-posterior radiographs have been extensively studied since the first assumption that these are found to show an individual pattern like fingerprints (Hashimoto et al., 2003). It has been proven that there are not two people with the same frontal sinuses, even being monozygotic twins (Quatrehomme et al.).

It is required to have an anterior radiograph for comparison purposes; otherwise, the analysis is not possible, which is a shortcoming of the method. However, if there is an ante-mortem image the professional should to use this sort of scientific exam to human identification (da Silva et al.; Silva et al.).

Although the frontal sinuses can provide detailed evidence for the forensic investigation, these may not be present in some individuals due to pathologic or genetic reasons. This fact can be attested in a study by Aydinlioblu et al., who bilateral aplasia of the frontal sinuses in $3.8 \%$ of the participants.

The identification of a body in decomposition is very difficult and has severe social and legal implications. Especially after important thanatological changes that occur in the cadaver, the comparison between radiographic images of body and those of the missing person is a peculiar identification method. Nevertheless, some shortcomings can be listed regarding this method: subjectivity, dependence on the professional expertise and, secondarily, the radiographic image can be significantly changed according to the incidence of the X-rays beam. In a study by Riepert et al., the frontal sinuses were found to show high variance between individuals (80.5\%) and it was confirmed that the direction of X-ray beam can cause important changes in the obtained images. 


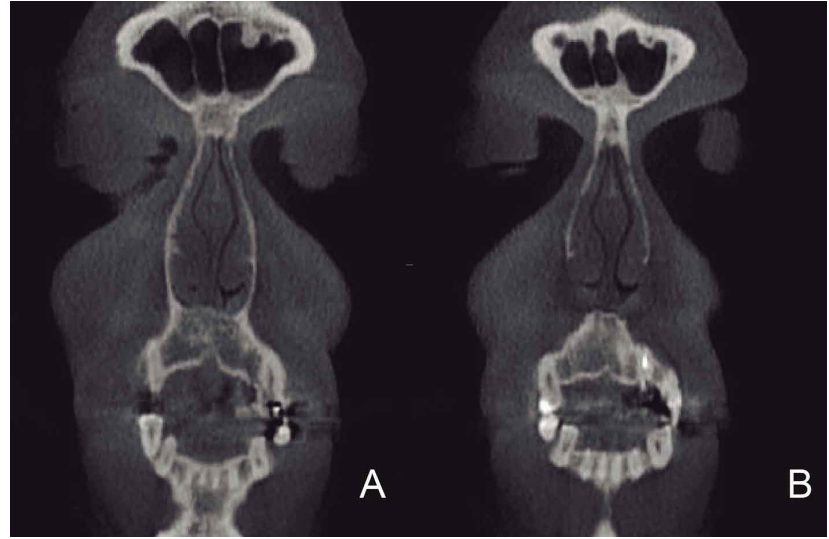

Fig. 1. A and B. Coronal images of the frontal sinus at different positions (the most posterior and the most anterior, respectively).

These limitations can be managed with technological resources, which have become increasingly common. Given this, computed tomography represents a complementary method with higher precision and many advantages over the conventional radiographic exam.

The use of cone-beam computed tomography stands out because the patient is benefited with low-dose radiation exposure compared with that for obtaining images in helical CT scanners (Hashimoto et al.). This fact can favor doctors and dental surgeons to indicate this method to obtain tomographic images of the face.

Some studies (Reichs, 1993; Smith et al.; Aydinlioglu et al.; Yang et al.; Lee et al., 2004) have described the use of computed tomography to observe the frontal sinuses anatomy and features. Cone-beam CT can become a rich source of data for forensic investigations, taking into account that it has become more accessible for the population. Reichs points out that CT allows many comparisons of the frontal sinus configuration in different levels.

Based on the scientific literature and considering that CT generates 2D images from a three-dimensional volume, it has been known that this images can vary in the same sinus (Fig. 1A and 1B), depending on the area sliced. In the present study, the adoption of some anatomic references to obtain axial slicing is suggested and, consequently, the others slices in 2D images to be used in the comparison between the frontal sinuses.

As seen in figure 2A, the axial slicing is suggested to be tangent to the upper limits of the orbital cavities, resulting in an image that makes possible to evaluate the frontal sinus structures with regard to the anterior-posterior and laterallateral directions (Fig. 2B). In order to observe the lower and upper limits of the frontal sinus, this study suggests a sagittal slicing through the patient's medial line (Fig. 2A green line, with results shown in Figure 2C).

Coronal slicing is not indicated to obtain frontal sinus images for comparative purposes due to the difficulty in establishing anatomic references. Therefore, slices that simulate different dispositions of the frontal sinus can be generated depending on the level where these were made, as exemplified in Figures 1A and 1B.

In case of a necessary comparison an ante-mortem posterior-anterior radiograph, one can re-make a slice on the frontal sinus area with $20 \mathrm{~mm}$ thickness thereby creating an excellent comparative image (Figs. 3A and 3B). Another advantage of $\mathrm{CT}$ technique lies in the possibility to obtain many posterior-anterior images, simulating the incidence of a comparative image obtained before death.

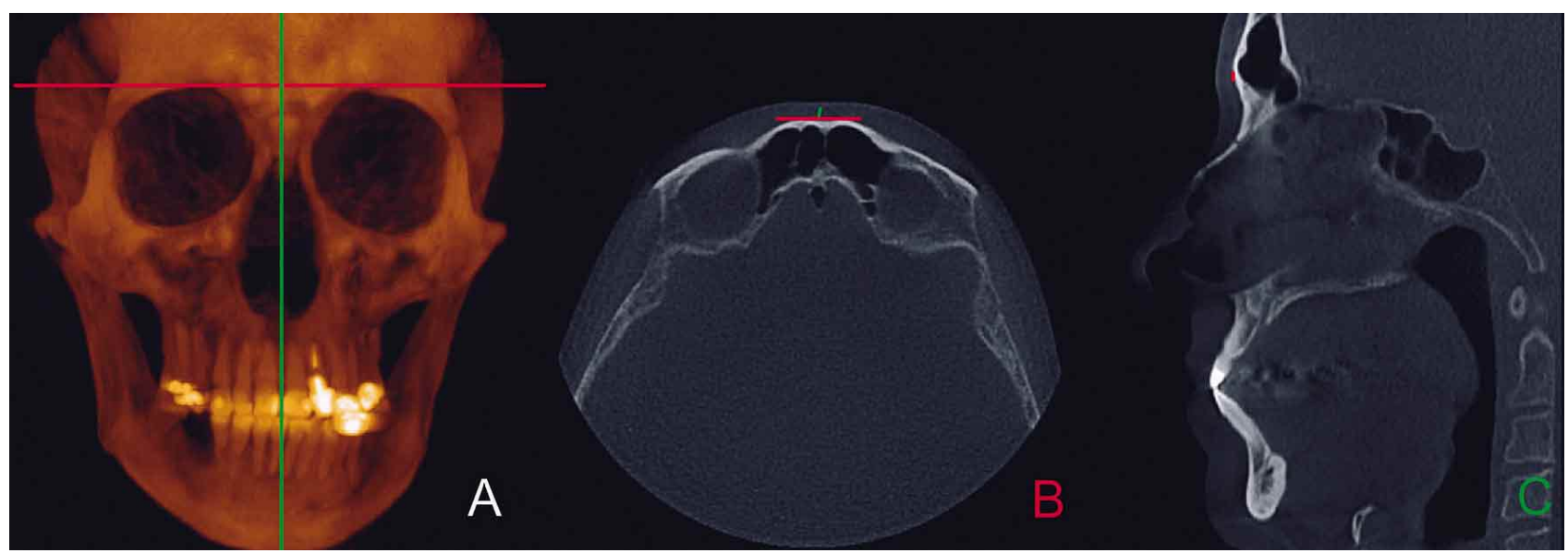

Fig. 2. A. 3D-image of the cranium with a red line hitting the upper limit of the orbital cavity; B. Axial slice exhibiting the anteroposterior and lateral-lateral limits of the frontal sinus; C. Sagittal slice exhibiting the upper and lower limits of the frontal sinus. 


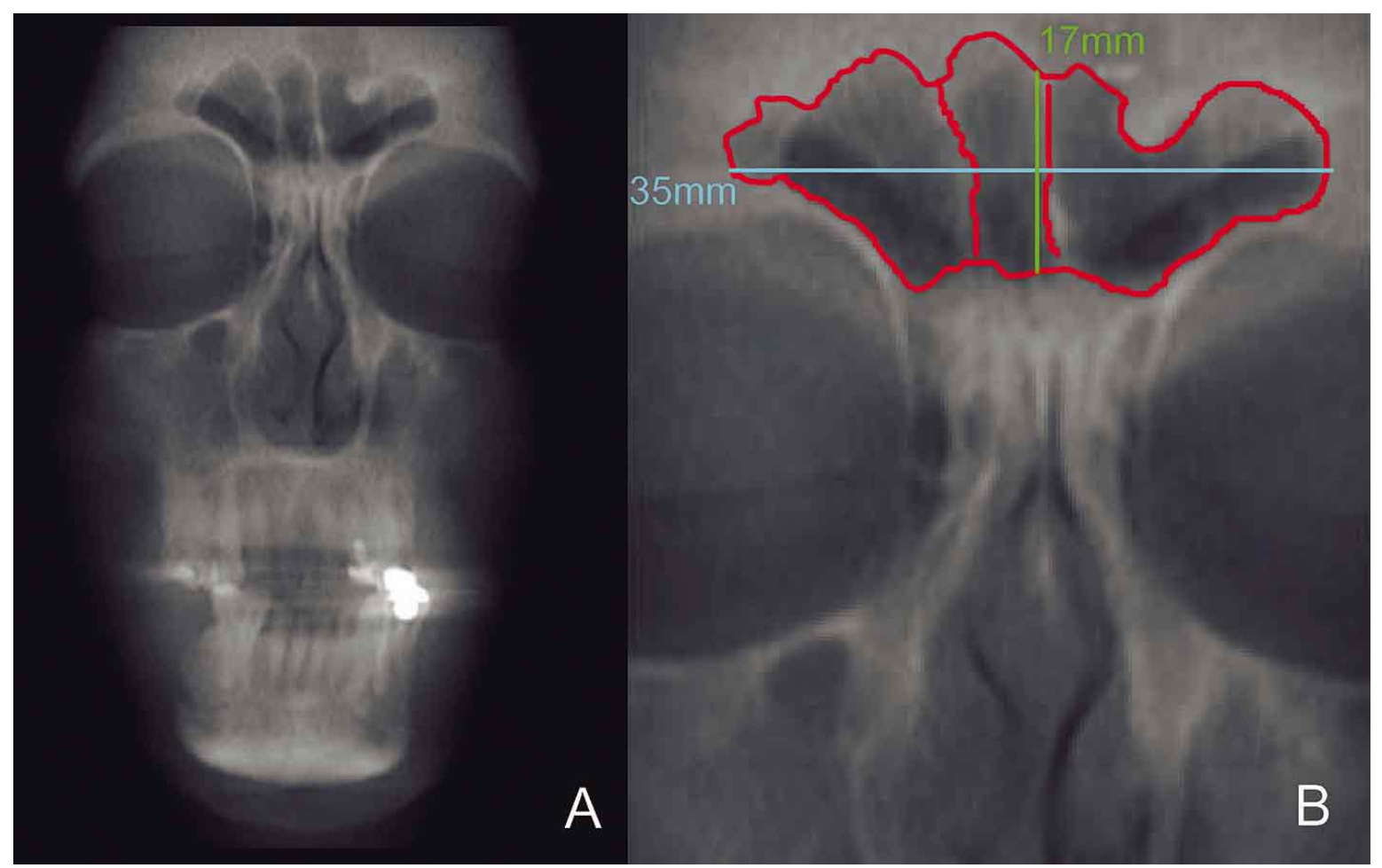

Fig. 3. A. Coronal image showing the frontal sinus in the anteroposterior view; B. Delineation of the frontal sinus contours, including width and height values.

As a result of the increasing violence rates, crimes have improved and become more sophisticated so bringing about the need for new scientific techniques to be used in the forensic investigation. The forensic expert should have knowledge that the dental or medical investigation is based on a collection of data, and it is necessary to have a sum of coincident evidence to support a technical and unquestioned inference.

In conclusion, the frontal sinuses can provide significant evidence for forensic identification. The peculiarity of the frontal sinus contours allows a precise and meticulous analysis, reducing the risk of errors on the part of the forensic experts. The comparison of frontal sinus images by cone-beam computed tomography can be used as an additional method in the identification process, providing the expert with greater reliability.

As crimes have become increasingly sophisticated, new forensic investigation techniques need to be improved and developed following the emergence of new technological resources.

MARQUES, J.A. M.; MUSSE, J. O.; GOIS, B. C.; GALVÃO, L. C. C. \& PARANHOS, L. R. Análisis de tomografías computarizadas de haz cónico del seno frontal en la investigación forense. Int. J. Morphol., 32(2):660-665, 2014.

RESUMEN: Los senos frontales pueden proporcionar evidencia significativa para la identificación forense. La peculiaridad de los contornos del seno frontal permite un análisis preciso y meticuloso, lo que reduce el riesgo de errores por parte de los expertos forenses. Describir la utilización de la tomografía computarizada de haz cónico como una alternativa para obtener imágenes de los senos frontales. Además, se propone la adopción de algunas referencias anatómicas para el corte axial, que deberían tener su plano tangente al límite superior de las cavidades orbitales, así como para el corte sagital, que debería ser realizado bajo la línea mediana. Así, los contornos de los senos serían bien observados y el margen de error en la obtención de imágenes comparativas se reduciría. La comparación de imágenes del seno frontal por tomografía computarizada de haz cónico es un método adicional en el proceso de identificación, ofreciendo al profesional una mayor fiabilidad.

PALABRAS CLAVE: Tomografía computarizada; Seno frontal; Medicina forense. 


\section{REFERENCES}

Alves, E. S. Medicina legal e deontologia. Curitiba, 1965.

Araki, K.; Maki, K.; Seki, K.; Sakamaki, K.; Harata, Y.; Sakaino, R.; Okano, T. \& Seo, K. Characteristics of a newly developed dentomaxillofacial X-ray cone beam CT scanner (CB MercuRay): system configuration and physical properties. Dentomaxillofac. Radiol., 33(1):51-9, 2004.

Arbenz, G. O. Medicina legal e antropologia forense. São Paulo, Atheneu, 1988.

Aydinlioglu, A.; Kavakli, A. \& Erdem, S. Absence of frontal sinus in Turkish individuals. Yonsei Med. J., 44(2):215-8, 2003.

Cameriere, R.; Ferrante, L.; Mirtella, D.; Rollo, F. U. \& Cingolani, M. Frontal sinuses for identification: quality of classifications, possible error and potential corrections. J. Forensic. Sci., 50(4):770-3, 2005.

Figini A. R. L.; Leitão e Silva, J. R.; Jobim, L. F. \& Dilva, M. Identificação humana. $2^{\mathrm{a}}$ ed. São Paulo, Milennium, 2003.

França, G. Medicina Legal. $7^{\text {a }}$ ed. Rio de Janeiro, Guanabara Koogan, 2004.

Hashimoto, K.; Arai, Y.; Iwai, K.; Araki, M.; Kawashima, S. \& Terakado, M. A comparison of a new limited cone beam computed tomography machine for dental use with a multidetector row helical CT machine. Oral Surg. Oral Med. Oral Pathol. Oral Radiol. Endod., 95(3):371-7, 2003.

Jayaprakash, P. T.; Srinivasan, G. J. \& Amravaneswaran, M. G. Cranio-facial morphanalysis: a new method for enhancing reliability while identifying skulls by photo superimposition. Forensic Sci. Int., 117(1-2):121-43, 2001.

Kirk, N. J.; Wood, R. E. \& Goldstein, M. Skeletal identification using the frontal sinus region: a retrospective study of 39 cases. J. Forensic. Sci., 47(2):318-23, 2002.

Lee, W. T.; Kuhn, F. A. \& Citardi, M. J. 3D computed tomographic analysis of frontal recess anatomy in patients without frontal sinusitis. Otolaryngol. Head Neck Surg., 131(3):164-73, 2004.

Mol, A.; Proffit, W. R.; Cevidanes, L. H. \& Bailey, L. J. Conebeam CT image analysis of condylar changes following orthognathic surgery. Oral Surg. Oral Med. Oral Pathol. Oral Radiol. Endod., 99(3):E26, 2005.

Prossinger, H. \& Bookstein, F. L. Statistical estimators of frontal sinus cross section ontogeny from very noisy data. J. Morphol., 257(1):1-8, 2003.

Quatrehomme, G.; Fronty, P.; Sapanet, M.; Grévin, G.; Bailet, P. $\&$ Ollier, A. Identification by frontal sinus pattern in forensic anthropology. Forensic Sci. Int., 83(2):147-53, 1996.
Reichs, K. J. Quantified comparison of frontal sinus patterns by means of computed tomography. Forensic Sci. Int., 61(23):141-68, 1993.

Ribeiro, F. A. Standardized measurements of radiographic films of the frontal sinuses: an aid to identifying unknown persons. Ear Nose Throat J., 79(1):26-8, 30, 32-3, 2000.

Riepert, T.; Ulmcke, D.; Schweden, F. \& Nafe, B. Identification of unknown dead bodies by X-ray image comparison of the skull using the X-ray simulation program FoXSIS. Forensic Sci. Int., 117(1-2):89-98, 2001.

Silva, R. F.; Botelho, T. L.; Prado, F. B.; Kawagushi, J. T.; Daruge Júnior, E. \& Bérzin. F. Human identification based on cranial computed tomography scan: a case report. Dentomaxillofac. Radiol., 40(4):257-61, 2011.

da Silva, R. F.; Prado, F. B.; Caputo, I. G.; Devito, K. L.; Botelho, T. de L. \& Daruge Júnior, E. The forensic importance of frontal sinus radiographs. J. Forensic Leg. Med., 16(1):18-23, 2009.

Silva, M. Compêndio de Odontologia Legal. São Paulo, Medsi, 1997.

Smith, D. R.; Limbird, K. G. \& Hoffman, J. M. Identification of human skeletal remains by comparison of bony details of the cranium using computerized tomographic (CT) scans. $J$. Forensic Sci., 47(5):937-9, 2002.

Vanrell, J. P. Odontologia legal e antropologia forense. 2nd ed. Rio de Janeiro, Guanabara Koogan, 2009.

Yang, Q. T.; Shi, J. B.; Kang, Z.; Chen, H. X.; Wang, T.; Lü, J. T. \& $\mathrm{Xu}, \mathrm{G}$. Computer-assisted anatomical study of nasofrontal region. Zhonghua Er Bi Yan Hou Ke Za Zhi, 39(6):349-52, 2004.

Correspondence to:

Prof. Luiz Renato Paranhos

Padre Roque St.

Mogi Mirim/SP -Zip Code: 13800-033

BRAZIL

Email: paranhos@ortodontista.com.br

Accepted: 02-05-2014

Received: 03-05-2013 